\title{
Prohibición del uso de animales en circos en México. Síntesis del acuerdo para resolver los Autos del incidente de suspensión relativo al Juicio de Amparo indirecto promovido por la Unión Nacional de Empresarios y Artistas de Circos Mexicanos contra la Ley Estatal de Fauna del Estado de Morelos, que prohíbe los animales en los $\operatorname{circos}^{1}$.
}

\section{Elizabeth Montero Romero ${ }^{2}$}

El día 28 de marzo de 2014 la Unión Nacional de Empresarios y Artistas de Circos Mexicanos (Asociación Civil), representada legalmente por Luis Manuel Torres Ramos, presentó escrito demandando el amparo y la protección de la Justicia Federal Mexicana, junto con la suspensión de los actos reclamados del Congreso del Estado de Morelos y otras autoridades, reclamando la aprobación, discusión, expedición, sanción, promulgación, refrendo y publicación de la Ley Estatal de Fauna del Estado de Morelos, donde se prohíbe los animales en los circos.

José Leovigildo Martínez Hidalgo, Juez Segundo de Distrito en el Estado de Morelos, al valorar las pruebas admitidas y desahogarlas, expone que la parte impetrante de garantías ofreció pruebas documentales, consistentes en el acuse original de veintiséis de marzo de dos mil catorce, copia certificada del instrumento notarial sesenta y cinco mil ochocientos veintiuno, lista de circos registrados ante la Secretaría de Medio Ambiente y Recursos Naturales, así como copia simple del Periódico Oficial "Tierra y Libertad" del Estado de Morelos, con lo anterior, el representante legal de la parte quejosa acreditó la personalidad con la que se ostenta, así como la existencia de la Ley reclamada en esta instancia.

Asimismo dicho Juez señala que es correcto haber señalado como autoridades responsables del acto reclamado al Congreso del Estado de Morelos, al Gobernador Constitucional del Estado de Morelos, al Secretario de Gobierno y por último al Director del Periódico Oficial "Tierra y Libertad" del Estado de Morelos.

Sin embargo, el Juez expone:

\footnotetext{
${ }^{1}$ http://www.derechoanimal.info/bbdd/Documentos/1407.pdf

2 Abogada. Miembro voluntario desde mayo de 2013 tanto en la Fundación Dejando Huella como en el Consejo Ciudadano de Derecho de los Animales (Puebla, México). Estudiante del Máster en Derecho Animal y Sociedad, UAB (3a. Edición).
} 
"En atención a lo dispuesto por los artículos 128 y 138, fracción I, de la Ley de la Materia, se niega la suspensión definitiva del acto reclamado, consistente en la aprobación, discusión, expedición, sanción, promulgación, refrendo y publicación de la Ley Estatal de Fauna del Estado de Morelos, toda vez que revisten el carácter de actos consumados, contra los cuales resulta improcedente conceder la providencia cautelar solicitada, en razón de equivaldría a otorgar efectos restitutorios, los cuales son propios de la sentencia que se dicte en el juicio principal del que emana el presente cuaderno incidental..." (Lo subrayado tiene sólo la finalidad de enfatizar).

Otro aspecto de nuestro interés que el Juez consideró en este acuerdo es que cuando se cuestiona la constitucionalidad de un ordenamiento (Ley Estatal de Fauna del Estado de Morelos), para efectos de concederse la antes citada suspensión, se debe cumplir con los requisitos previstos en el artículo 128 de la Ley de Amparo, lo cual no acontece, pues dicho precepto señala:

"Artículo 128. Con excepción de los casos en que proceda de oficio, la suspensión se decretará, en todas las materias, siempre que concurran los requisitos siguientes: I. Que la solicite el quejoso; y II. Que no se siga perjuicio al interés social ni se contravengan disposiciones de orden público. La suspensión se tramitará en incidente por separado y por duplicado". (Lo subrayado tiene sólo la finalidad de enfatizar).

Continuando la redacción del Juez Segundo de Distrito del Estado de Morelos como sigue:

"Lo que significa que para decidir sobre la suspensión de los actos reclamados, cuando su naturaleza lo permita, este juzgador debe realizar un análisis ponderado de la apariencia del buen derecho y de la afectación al interés social, lo que implica un estudio sucesivo sobre los aspectos preliminares, esenciales y legales de dicha medida cautelar, esto es, en primer lugar, la existencia de dichos actos y al respecto, se tienen por ciertos pues la existencia de la norma impugnada es patente al ser un hecho notorio para este juzgador su publicación que data del diecinueve de marzo de dos mil catorce, donde expresamente prohíbe los animales en los circos, además, establece que todos los lugares de recreación y cautiverio de animales como ferias y zoológicos públicos, se deberá proporcionar a los animales, locales adecuados que les permitan libertad de movimiento, así como alimentación suficiente y condiciones climatológicas necesarias, de acuerdo a su especie.

Durante el traslado de cualquier animal, deberán revisarse las condiciones de higiene y seguridad necesarias de éste, y no podrán ser inmovilizados en posiciones que le causen lesiones o sufrimiento; asimismo establece que son faltas 
y sanciones en materia de fauna cualquier acto de crueldad intencional o imprudencial en cualquier animal, lo cual se entiende, entre otros, la utilización de animales en espectáculos públicos o privados cuando dicha utilización sea para infligir maltrato intencional al animal, ocasionándole afectaciones en su integridad física, así como toda privación de aire, luz, alimento, agua o espacio suficiente que cause o pueda causar daño a la vida normal de un animal.

Acto seguido se analiza la posibilidad de suspender las consecuencias legales de dicha prohibición a la luz de la apariencia del buen derecho que le asiste la parte quejosa en obtener la suspensión provisional de los actos reclamados el que debe ser ponderado con el nivel de afectación que el otorgamiento de la suspensión pudiera ocasionar al interés de la colectividad, frente al que podría ocasionar al quejoso." (Lo subrayado tiene sólo la finalidad de enfatizar).

Añade además aquel Juez de Distrito, que es evidente el derecho de la persona moral quejosa de dedicarse de manera asociada a la actividad circense dentro de la cual ofrece espectáculos con animales vivos, actividad que se encuentra reflejada en el artículo 50 Constitucional Mexicano del tenor literal siguiente:

"Artículo $5^{\circ}$.- A ninguna persona podrá impedirse que se dedique a la profesión, industria, comercio o trabajo que le acomode, siendo lícitos. El ejercicio de esta libertad sólo podrá vedarse por determinación judicial, cuando se ataquen los derechos de tercero, o por resolución gubernativa, dictada en los términos que marque la ley, cuando se ofendan los derechos de la sociedad. [...]"(Lo subrayado tiene sólo la finalidad de enfatizar).

De igual forma, se funda el Juez de distrito Martínez Hidalgo en el artículo 88 del Código Federal de Procedimientos Civiles, de aplicación supletoria a la Ley de Amparo, donde se invoca como hecho notorio la Ley Estatal de Fauna, publicada en el periódico Oficial "Tierra y Libertad" el diecinueve de marzo de dos mil catorce en cuyo artículo 13, el cual establece que en todos los lugares de recreación y cautiverio de animales como ferias y zoológicos públicos, se deberá proporcionar a los animales, locales adecuados que les permitan libertad de movimiento, así como alimentación suficiente y condiciones climatológicas necesarias, de acuerdo a su especie. Durante el traslado de cualquier animal, deberán revisarse las condiciones de higiene y seguridad necesarias de éste, y no podrán ser inmovilizados en posiciones que le causen lesiones o sufrimiento.

Asimismo, las fracciones V y VII del artículo 69 de la citada Ley de Fauna, establecen que:

"Artículo 69.- Son faltas y sanciones en materia de fauna, la captura de animales que formen parte de la lista de especies en estado de extinción y cualquier acto de 
crueldad intencional o imprudencial ejecutado en cualquier animal. Para efectos de aplicación de sanciones, se entenderá por actos de crueldad los siguientes:

[...]

V.- Utilización de animales en espectáculos públicos o privados cuando dicha utilización sea para infligir maltrato intencional al animal, ocasionándole afectaciones en su integridad física, tales como heridas cualquiera que sea su gravedad o su muerte, con excepción de lo establecido en el artículo 12.

$[\ldots]$

VII.- Toda privación de aire, luz, alimento, agua o espacio suficiente que cause o pueda causar daño a la vida normal de un animal;"

Finalmente, el artículo 71 bis de esta misma Ley dispone lo siguiente:

"Artículo 71 bis.- Se impondrá multa de mil quinientos a dos mil días de salario mínimo vigente en el Estado, y arresto hasta por treinta y seis horas a quien realice la infracción contenida en el segundo párrafo del artículo 12 de la presente Ley.

Así mismo se procederá a la clausura del inmueble donde se desarrolle el evento o espectáculo".

Acto seguido, el Juez citó la jurisprudencia P./J. 74/2006, sustentada por el Pleno de la Suprema Corte de Justicia de la Nación, publicada en el Semanario Judicial de la Federación y su Gaceta, tomo XXIII, Junio de 2006, cuyo rubro y texto es del tenor literal siguiente:

"HECHOS NOTORIOS. CONCEPTOS GENERAL Y JURÍDICO. Conforme al artículo 88 del Código Federal de Procedimientos Civiles los tribunales pueden invocar hechos notorios aunque no hayan sido alegados ni probados por las partes.

Por hechos notorios deben entenderse, en general, aquellos que por el conocimiento humano se consideran ciertos e indiscutibles, ya sea que pertenezcan a la historia, a la ciencia, a la naturaleza, a las vicisitudes de la vida pública actual o a circunstancias comúnmente conocidas en un determinado lugar, de modo que toda persona de ese medio esté en condiciones de saberlo; y desde el punto de vista jurídico, hecho notorio es cualquier acontecimiento de dominio público conocido por todos o casi todos los miembros de un círculo social en el momento en que va a pronunciarse la decisión judicial, respecto del cual no hay duda ni discusión; de manera que al ser notorio la ley exime de su prueba, por ser del conocimiento público en el medio social donde ocurrió o donde se tramita el procedimiento." (Lo subrayado tiene sólo la finalidad de enfatizar). 
De ahí que concluye el Juez Segundo de Distrito del Estado de Morelos que al ponderar el interés particular de la agrupación quejosa de dedicarse de manera asociada a la actividad que desee confrontado con el interés que tiene la sociedad de evitar el sufrimiento y maltrato de la fauna y los animales, se colige que aquella derrota y prevalece sobre los intereses particulares de la parte quejosa.

Añade que si bien es cierto, conforme al numeral 5 de la Ley Suprema, a ninguna persona podrá impedirse que se dedique a la profesión, industria, comercio o trabajo que le acomode, siendo lícitos y mientras no se ofendan los derechos de la sociedad; no menos cierto es que con las disposiciones contenidas en la Ley Estatal de Fauna, existe un mayor beneficio social, pues con ello se propicia el desarrollo de actitudes de respeto hacia la fauna, se busca evitar que distintas especies de animales sean expuestas a actos de crueldad y dolor de manera innecesaria, así mismo, para contribuir a la formación del individuo y a su superación personal, familiar y social, inculcándole actitudes responsables y humanitarias hacia los animales, además de procurar erradicar en todas sus formas el maltrato y los actos de crueldad hacia ellos; interés público que predomina sobre el interés particular del que, se advierte, busca preservar el quejoso con la suspensión del acto reclamado, y que si bien es cierto, el negar la medida cautelar solicitada podría causarle un perjuicio, en la medida que probablemente ocasionaría un detrimento en su patrimonio al dejar de percibir un ingreso por la actividad a la que refiere dedicarse (circense), también es verdad que, como ya se detalló, el interés de la sociedad tiene mayor jerarquía y debe prevalecer ante el interés particular.

Aunado a lo anterior, el Juez señala que los circos agrupados en la asociación no exhibieron documento alguno con el que se acreditara que cuentan con los permisos y autorizaciones para la presentación de animales en los espectáculos público o privados.

A continuación trajo como sustento a lo anterior la tesis I.40.A.70 K, emitida por el Cuarto Tribunal Colegiado en Materia Administrativa del Primer Circuito, correspondiente a la Novena Época, que señala:

"SUSPENSIÓN EN EL AMPARO. CONFORME A LA TEORÍA DE PONDERACIÓN DE PRINCIPIOS DEBE NEGARSE SI EL INTERÉS SOCIAL CONSTITUCIONALMENTE TUTELADO ES PREFERENTE AL DEL PARTICULAR.

Cuando dos derechos fundamentales entran en colisión, se debe resolver el problema atendiendo a las características y naturaleza del caso concreto, conforme al criterio de proporcionalidad, ponderando los elementos $o$ subprincipios siguientes:

a) idoneidad, la cual es la legitimidad constitucional del principio adoptado como preferente, por resultar ser el adecuado para el logro de un fin constitucionalmente válido o apto para conseguir el objetivo pretendido; 
b) necesidad, consistente en que no exista otro medio menos limitativo para satisfacer el fin del interés público y que sacrifique, en menor medida, los principios constitucionales afectados por el uso de esos medios; o sea, que resulte imprescindible la restricción, porque no exista un medio menos oneroso, en términos del sacrificio de otros principios constitucionales, para alcanzar el fin deseado y que afecten en menor grado los derechos fundamentales de los implicados;

c) el mandato de proporcionalidad entre medios y fines implica que al elegir entre un perjuicio y un beneficio a favor de dos bienes tutelados, el principio satisfecho o que resulta privilegiado lo sea en mayor proporción que el sacrificado. Esto es que no se renuncie o sacrifiquen valores y principios con mayor peso o medida a aquel que se desea satisfacer. Así, el derecho o principio que debe prevalecer, en el caso, es aquel que optimice los intereses en conflicto y, por ende, privilegiándose el que resulte indispensable y que conlleve a un mayor beneficio o cause un menor daño.

Consecuentemente, tratándose de la suspensión debe negarse dicha medida cautelar cuando el interés social constitucionalmente tutelado es preferente al del particular, ya que el derecho o principio a primar debe ser aquel que cause un menor daño y el que resulta indispensable privilegiarse, o sea, el que evidentemente conlleve a un mayor beneficio." (Lo subrayado tiene sólo la finalidad de enfatizar).

Así pues, el Juez de Distrito resuelve negar la suspensión definitiva solicitada promovida por Luis Manuel Torres Ramos, representante legal de la Unión Nacional de Empresarios y Artistas de Circos Mexicanos, Asociación Civil, respecto de las consecuencias jurídicas del acto reclamado, esto es: la aprobación, discusión, expedición, sanción, promulgación, refrendo y publicación de la Ley Estatal de Fauna del Estado de Morelos.

Es importante señalar, sin duda esto es un buen precedente dentro de la innovadora rama del Derecho Animal en México, ya que es un juez federal quien se ha mostrado a favor de la protección de los animales con base en la ponderación del interés particular de la agrupación cirquense de dedicarse de manera asociada a la actividad que desee (utilizando a los animales) confrontado con el interés que tiene la sociedad de evitar el sufrimiento y maltrato de la fauna y los animales, se desprende que éste último interés es el prioritario y que prevalece sobre los intereses particulares de la agrupación cirquense.

Al final, habrá que esperar la resolución en el mes siguiente del año en curso donde el Juez de Distrito niegue o conceda el amparo en cuanto al expediente principal, puesto que este acuerdo sólo radicó en resolver si se concedía o no la suspensión de los actos antes mencionados. 